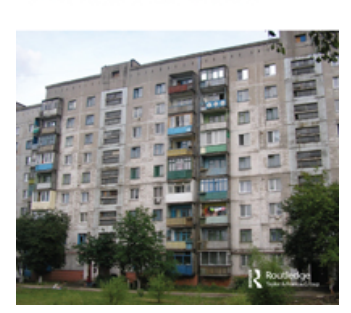

\title{
Elderly co-residence and the household responsibilities hypothesis: evidence from Nanjing, China
}

\section{Jianxi Feng, Martin Dijst, Bart Wissink \& Jan Prillwitz}

To cite this article: Jianxi Feng, Martin Dijst, Bart Wissink \& Jan Prillwitz (2015) Elderly coresidence and the household responsibilities hypothesis: evidence from Nanjing, China, Urban Geography, 36:5, 757-776, DOI: 10.1080/02723638.2015.1039407

To link to this article: http://dx.doi.org/10.1080/02723638.2015.1039407

曲 Published online: 06 May 2015.

Submit your article to this journal $\lceil\pi$

山ll Article views: 104

Q View related articles $\sqsubset$

View Crossmark data ¿ 


\title{
Elderly co-residence and the household responsibilities hypothesis: evidence from Nanjing, China
}

\author{
Jianxi Feng ${ }^{\mathrm{a} *}$, Martin Dijst ${ }^{\mathrm{a}}$, Bart Wissink ${ }^{\mathrm{b}}$ and Jan Prillwitz ${ }^{\mathrm{a}}$ \\ ${ }^{a}$ Faculty of Geosciences, Utrecht University, Utrecht, The Netherlands; ${ }^{b}$ Department of Public \\ Policy, City University of Hong Kong, Kowloon Tong, Hong Kong
}

(Received 18 April 2013; accepted 29 January 2015)

\begin{abstract}
In this paper, we analyze the effects of co-residence with elderly parents on gender differences in travel. The Household Responsibility Hypothesis (HRH) explains differences in the role of women regarding household responsibilities. However, research so far has studied "Western" household types while excluding households with coresiding elderly parents. Furthermore, research has paid exclusive attention to gender differences in commuting trips, and has neglected the effects of built environment characteristics. In view of these shortcomings, we pose the following research questions: what are the determinants of gendered differences in travel behavior, and specifically, what are the effects of elderly co-residence in households and land use on gender differences in trip frequency and travel distance? In addition to the $\mathrm{HRH}$, we introduce the Elderly Co-residence Hypothesis, which suggests that co-residing elderly parents take over household responsibilities from adult women, resulting in diminishing gender differences in working-age travel patterns. We present the results of empirical research in Nanjing, China, that support this hypothesis.
\end{abstract}

Keywords: transportation; commuting; gender; Nanjing; China

\section{Introduction}

The differences between the travel patterns of men and women have been and will remain a hot topic of debate in the academic community and in policy circles (Hubers, Schwanen, $\&$ Dijst, 2011). On the basis of data sets from different geographic areas, studies conclude that women make more daily trips but travel fewer miles. Women tend to commute over shorter distances while making more household support trips (Crane, 2007; Rosenbloom, 2006). There are different explanations for these gender differences. Among these, the Household Responsibility Hypothesis (HRH) is the most widely cited. This hypothesis attributes women's short commutes to the fact that women tend to take on more household and childcare responsibilities (Turner \& Niemeier, 1997). Alternative explanations focus on the lower wages of women, on the spatial distribution of female-dominated occupations, and on the spatial segregation of labor markets (Hanson \& Pratt, 1988; Lee \& McDonald, 2003; MacDonald, 1999).

In this paper, we aim to make a threefold contribution to this work on gender differences in travel behavior. First, the existing research has typically focused on gender relations in the dominant Western household types - couples and core families - and has

*Corresponding author. Email: jxfup@nju.edu.cn

Present address for Jianxi Feng is Department of Urban Planning and Design, School of Architecture and Urban Planning, Nanjing University, China. 
paid little attention to other household types. Gender variations in other household types might paint a different picture, particularly in East Asia, where it is still the norm for elderly parents to co-reside with their adult children and grandchildren (Cohen, 1998; Wang, Schoebi, \& Perrez, 2010). However, the effects of the presence of elderly parents on the allocation of household tasks between women and men and the resultant travelactivity behavior still remain largely unknown.

Second, land use might affect the travel behavior of men and women differently. However, whereas there is considerable work on the links between land-use characteristics and travel patterns (Ewing \& Cervero, 2001; Feng, Dijst, Prillwitz, \& Wissink, 2013), less effort has been devoted to revealing how land use may interact with gender to influence travel patterns (for an exception, see Hanson, Kominiak, \& Carlin, 1997). Therefore, we will include the effects of some location factors in our study of gender differences.

Third, the existing research places an overwhelming emphasis on trips to work while overlooking other destinations (Hall, 2004; Rosenbloom, 2006). Kwan (2000) claims that the emphasis on commuting does not adequately reflect the mobility constraints faced by women and men, resulting in a "distorted" view of travel patterns. Thus, research on gender differences in travel behavior for non-work purposes is also needed.

To address these gaps in the existing literature, in this paper we answer the following research question: what are the determinants of gendered differences in travel behavior, and specifically, what are the effects of elderly co-residence in households and land use on gender differences in trip frequency and travel distance? We studied the question in Nanjing, China, where co-residence with the elderly is common. With the help of the Nanjing Residents Travel Survey (NRTS) of 2008, we answer the research question in five sections. After this introduction, the second section reviews the relevant literature on gender differences in travel behavior. This is followed by an overview of the research design in the third section. The fourth section presents a descriptive analysis of our data set, followed by various regression models in section five. The concluding sixth section answers the research questions.

\section{Literature review}

The HRH holds that gender differences in travel behavior can be attributed to the fact that women traditionally have the primary responsibility for the home and child care (Lee \& McDonald, 2003; Turner \& Niemeier, 1997), which consequently imposes significant temporal-spatial constraints that negatively affect travel frequency and travel distance. Despite widespread support for this hypothesis in the literature, empirical testing has produced mixed outcomes. Several studies confirm that household responsibilities contribute to shorter commutes for women. For instance, Hanson and Hanson (1980) show that women in Sweden make more trips for shopping than men but fewer for work and recreation. Lee and McDonald (2003) also observe that in Seoul, married women commute significantly shorter distances than married men. Additionally, they conclude that the presence of parents or parents-in-law in households reduces married women's responsibilities and increases women's commuting distances substantially. However, other research suggests that household responsibilities have a negligible influence. Hanson and Johnston (1985) find that women in Baltimore in households with children do not have shorter commuting distances than women in households without children. Crane (2007) comes to the same conclusion on the basis of a different data set, the American Housing Survey: the presence of children in the United States of America has no effect on women's commuting distances.

Research into gender differences in commuting distance is not limited to studies that test the HRH. Alternative explanations focus on occupational and labor market 
characteristics. Some scholars argue that gender disparities in commuting distances result from the low wages of women (Madden, 1981). Because the economic returns of female labor do not cover the costs of long work trips, women might increase their real wages through shorter commutes. Alternatively, others argue that shorter commutes result from the spatial pattern of female-dominated employment opportunities: because jobs for women are more evenly distributed than jobs for men, it is much easier for women to find a job close to home (Hanson \& Johnston, 1985; Hanson et al., 1997). The shorter commutes of women could also reflect a high spatial segmentation of the local labor market, which is a combined result of the job search strategies of employees and the location and hiring practices of employers (Hanson \& Pratt, 1995; MacDonald, 1999). Nonetheless, some scholars argue that more factors should also be addressed in the study of gendered travel behavior. For instance, on the basis of the survey of service workers in the New York Metropolitan Area, McLafferty and Preston (1991, 1992) examined the influence of race on commuting times, finding that females in the Black and Hispanic communities commute as far as their male counterparts. Workplace factors, such as income, occupation and job accessibility, are found to be important in explaining this lack of gender differences.

In addition to these studies of transportation and geography, sociological research on domestic work divisions also sheds light on the interpretation of gender differences in travel behavior (Kroska, 2003; Wang et al., 2010). For instance, the relative resource hypothesis focuses on the role of partner resources, such as earnings, education level, and occupational status, in the bargaining of domestic work divisions (Wang et al., 2010). This hypothesis suggests that partners with greater resources are more likely to negotiate their way out of domestic work, which is akin to the economic argument of Gary Becker (1971) that it is "rational" that the partner with the highest wages would spend more time at the salaried job (including the commute) and less time on domestic work to maximize utility. Another hypothesis in the sociology of domestic work divisions, the gender ideology hypothesis, posits that spouses with liberal attitudes divide domestic work more equitably than spouses with conservative or traditional attitudes (Kroska, 2003).

There is rather limited research investigating how a built environment influences the travel behavior of males and females differently. Drawing on panel data from the American Housing Survey, Crane (2007) revealed that high residential densities exert a smaller influence on males' than on females' commuting distances. With regard to maintenance purposes, the reverse is found: males' participation in out-of-home household maintenance activities is more sensitive to changes in population densities and the extent of land-use mixture than is females' participation (Schwanen, Ettema, \& Timmermans, 2007). The spatial distribution of different types of employment is also considered to influence the travel behavior of men and women. For example, Hanson and Pratt (1990) found that women employed in full-time "female-dominated" occupations have significantly shorter travel times than women employed in other occupations. It is notable that built environment variables might play a less important role for travel patterns than socioeconomic characteristics (Hanson, 1982).

The presence of elderly people in a household will provide more possibilities for the distribution of household responsibilities. Seniors could either reduce the household responsibilities of adult children or add another burden if the elderly require care. It would therefore be appropriate to control for the health status of these elderly co-resident parents (for instance, their age and health). However, we do not have any information on the health of the elderly. Our information on age is also rather rough; our database contains only a category of "older than 60 years". Therefore, we are unfortunately not 
able to distinguish the young elderly from the older elderly. We do observe in this context, however, that various scholars (e.g., Chen \& Silverstein, 2000; Goh, 2009) have found that in general, the co-residence of elderly will result in added support. Therefore, we hypothesize that due to the presence of elderly parents who share household responsibilities, in adult families and extended families, gender differences are smaller or even negligible. We name this hypothesis the Elderly Co-residence Hypothesis (ECH). In addition, we hypothesize that for commuting travel, women are more sensitive to differences in the population density and the provision of public transport than men, whereas for shopping travel, the reverse is assumed.

\section{Research design}

\section{Contextual difference between China and Western countries}

There are substantial differences between urban China and the West. In China, there is high female labor market participation. With employment ratios for women in China over $80 \%$, female labor market participation is significantly higher than in Iceland, which has the highest female labor participation rate in Europe with 71\% (World Bank, 2013). In our database, $95.6 \%$ of men have jobs, whereas $91.6 \%$ of women are employed. The percentage of dual-worker households among couples and core families is $89 \%$. An even more notable difference is that in China, hardly any part-time jobs are available. Therefore, women (and men) on the labor market will automatically be full-time workers (Fan \& Regulska, 2008). This observation is supported by international variations in the working hours gap between working men and women. In China, between 2001 and 2003, this gap was only 0.9 hours per week, whereas in 2004, the weekly gender gap was 15 hours in Switzerland, 11 hours in Italy and Norway, and 9 hours in Germany and Belgium (Federal Statistical Office, 2008).

Another prominent difference relates to the traditional gender roles in households. The cultural norms of China describe strict gender rules and requirements for men and women. The norms indicate that husbands and wives should manage different tasks in society, with women being in charge of domestic chores and men working outside the family (Zuo \& Bian, 2001). The influence of traditional gender ideologies is profound. In 2000, $43.8 \%$ of the investigated men and $37.4 \%$ of the investigated women in Nanjing agreed that it is the prime responsibility of men to take care of out-of-home social activities, whereas women were responsible for domestic household tasks (The Second Chinese Women's Social Status Survey Team, 2001). It is notable that high-quality care and education for preschool children, particularly for children younger than two years old, are insufficiently developed in China (Lamb, Sternberg, Hwang, \& Broberg, 2014). It is therefore not uncommon that a considerable portion of women in core families, particularly when workplaces are near the home, tend to go home to take care of their children during lunchtime (Du \& Dong, 2013).

A brief introduction to the transportation development and modal split in Nanjing seems necessary to enhance readers' understanding of the paper. Nanjing is still at the beginning of a process of massive motorization, and they had only one metro line in 2008 . Public transportation is insufficiently developed. People thus rely on non-motorized modes of transportation; walking and cycling are responsible for more than $65 \%$ of the total trips, whereas the share of private cars is only approximately $11 \%$, as indicated in Table 1 . The gender differences in mode choice are quite obvious. Women rely more than men do on non-motorized transportation. The share of private car use among women is 
Table 1. Mode choice of men and women in Nanjing.

\begin{tabular}{lrrr}
\hline & Male & Female & Total \\
\hline Walking & 22.4 & 31.4 & 27.1 \\
Cycling & 34.6 & 42.3 & 38.6 \\
Public transport & 18.5 & 18.9 & 18.7 \\
Car & 17.5 & 4.2 & 10.6 \\
Other & 7.0 & 3.2 & 5.0 \\
Total & 100.0 & 100.0 & 100.0 \\
\hline
\end{tabular}

Source: Own calculation based on data of NRTS 2008.

only $4.2 \%$, whereas this figure is $17.5 \%$ for men. The use of public transportation is virtually the same: both women and men take approximately $19 \%$ of their trips on public transportation.

\section{Operationalization of concepts}

According to time-geography, an individual's activities and travel in a day can be represented as a path in space-time within a "prism" defined by a set of constraints: capability constraints, coupling constraints and authority constraints (Hägerstraand, 2005). Activities that are fixed in space and time delimit a person's opportunity to participate in travel and other activities, thus imposing an important restriction on people's access and mobility. Therefore, activities act as "pegs" around which other activities are organized (Cullen, 1979; Dijst \& Vidakovic, 2000; Kwan, 1999; Schwanen, Kwan, \& Ren, 2008). Women and men in different households could have different allocations of household responsibilities. Household responsibilities, by virtue of their demand for time and effort, may exert an influence on household members' space-time fixity. That is, by taking care of different household responsibilities (some out-of-home activities themselves are undertaken as household responsibilities, such as shopping for the household), women and men tend to have different temporal-spatial constraints and different travel behavior, such as different commuting distances and shopping frequency.

The research from the literature review usually uses household characteristics as proxies for the degree of household responsibilities. For an exception, see Hanson and Pratt (1990), who present detailed data of household responsibilities by gender. Because the majority of this research has been conducted in Western settings, it is not surprising that the studies incorporate only proxies that relate to household types that are dominant in the West-particularly marital status, the presence of children, and household size-all of which are important drivers of the travel behavior of individuals.

However, in East Asia, household situations tend to be more varied, due to frequent co-habitation with elderly parents. As a result, here two more household types are common: "adult families", in which elderly live together with their adult (un)married children, and 'extended families', consisting of the elderly, their adult children and their grandchildren. To research the effects of co-habitation with elderly parents, in this study, we add another proxy: the presence of older parents. Therefore, in addition to single people, couples and families (the usual categories), we add adult family and extended family (Table 2). To avoid confusion, we adopt new terminology and replace "family" with "core families", "adult families" with "adult households", and "extended families" 
Table 2. Household types and its characteristics.

\begin{tabular}{ll}
\hline Household types & \multicolumn{1}{c}{ Characteristics } \\
\hline Single & $\begin{array}{l}\text { Single person } \\
\text { Couple/partner }\end{array}$ \\
Couple & $\begin{array}{l}\text { Households in which parents live with one or more child(ren) } \\
\text { Households in which the elderly live together with their adult (un)married } \\
\text { children but without grandchildren } \\
\text { Households in which the elderly live together with their adult (un)married } \\
\text { children and grandchildren }\end{array}$ \\
\hline
\end{tabular}

with "extended households". That is, we now have five different household types: single people, couples, core families, adult households and extended households.

It is worth noting that the household categories in our research can cover information on household size, the presence of children and the elderly, and composite effects. For instance, it is possible that single seniors are more likely than old couples to co-reside with their adult children for physiological and physical care. It is also possible that the presence of children and the presence of the elderly is interrelated. Due to time and energy limitations, young couples might invite their aged parents to live with them and offer help taking care of the children. There could be other measurements for household structures (Kwan, 1999), such as the number of children, the number of elderly parents, and the ratio of elderly parents to number of children. However, due to the one-child policy in China, most families have only one child. Therefore, variables relating to the number of children do not offer an effective index because they may not capture the composite effects discussed above. Instead, we adopted a nominal categorical variable for household types.

\section{Study area and data}

We studied our hypotheses in Nanjing, China. This city, the capital of Jiangsu Province, is the second largest commercial center in East China. It covers an area of 4,723 square kilometers and had a total population of 6.24 million in 2008 (Nanjing Statistic Bureau, 2008). We analyzed travel behavior in Nanjing on the basis of the NRTS, which was conducted by the Nanjing Urban and Transportation Planning and Designing Institution Limit Cooperation. The survey was sponsored by the Nanjing Transportation Planning Committee and was used for "The Nanjing Comprehensive Transportation Planning 2009" initiative. The survey covered 10 districts of Nanjing, and the data set includes 5,400 individuals of 1,800 households. Accessing the data set is rather expensive. By leaving out two districts (1,502 respondents), we were able to get, free of charge, the data of eight districts with 3,894 respondents (Figure 1). The two missing districts have sociodemographic compositions, built environments and development history similar to the adjacent included districts. Therefore, we reasonably expected that the travel behaviors of the residents of the two missing districts are adequately represented by the other districts. The sub-sample size of each district is proportional to its population. More Traffic Analysis Zones (TAZs) are selected in the districts with large populations. In each TAZ, 150 respondents from approximately 50 households are selected using a systematic random sampling method. The sampling frame is the list of households registered in the subdistrict. Because the household is the sampling unit, men and women are drawn from the same set of households. This travel database includes the socioeconomic and 


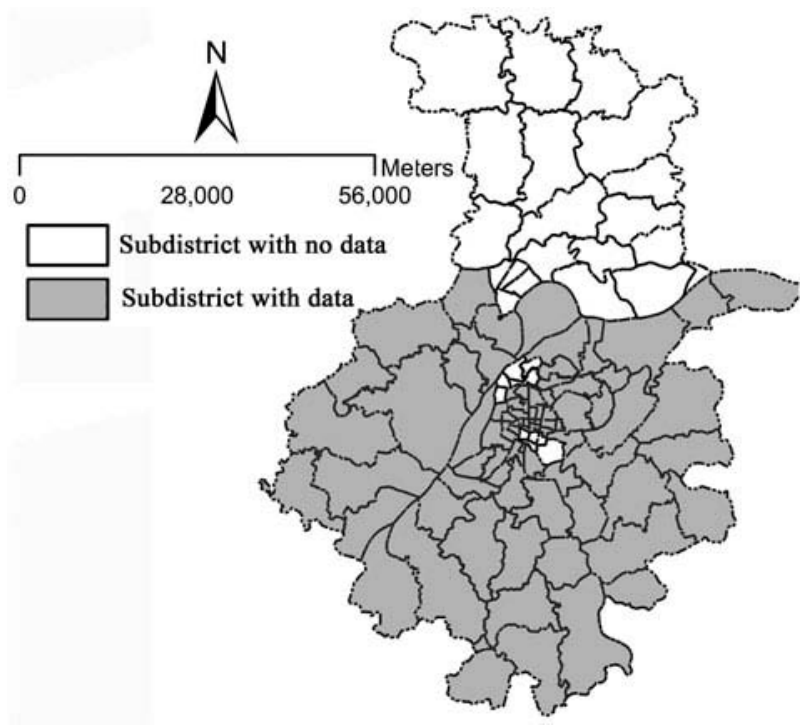

Figure 1. The map of Nanjing in China.

demographic attributes of the respondents, such as gender, age, education level, occupation, household income, household car ownership and detailed information, derived from one-day travel diaries on Tuesdays, Wednesdays and Thursdays in June 2008.

Because the purpose of this paper is to examine gendered travel behavior in urban China, particularly the influence of the presence of elderly in the household on the travel behavior of young male and female parents, we do not address the travel behavior of the elderly parents and parents-in-law of the young parents. Finally, we have 2,090 participants in total-1,065 male and 1025 female. In our descriptive analysis, we distinguish four trip purposes: commuting, shopping, leisure (social visits, sports, culture and recreation) and "other purposes" (including work-related travel, trips for studying, and accompanying children to/from school). We conduct multivariate analyses for commuting, shopping and leisure travel purposes. However, rather few independent variables are found to have significant effects for leisure travel. Therefore, in the paper, we show our analyses for only commuting and shopping travel. In line with the international literature, our analysis includes two types of independent variables: the socio-demographic attributes of travelers and built environment characteristics. Socio-demographic variables include gender, age, education level, occupation, household income, household car ownership and household type. Variables relating to the built environment include population density and distance to the nearest metro station. Population density is calculated at the subdistrict level of their residential locations. The subdistrict varies from 0.6 square kilometer in the central city to 2 square kilometers in the exurb. The distance to the nearest metro station is measured as straight line distance.

Obviously, the models below do not in themselves indicate causal relationships; they note only statistical correlations. Some of the explanatory variables in the models may also be affected by travel behavior (e.g., car ownership could be the result of a longer commuting distance), meaning that the causality of the relationships is not as clear-cut as the models suggest. We have considered the use of structural equation models to explore the direction of causality in greater depth. However, handling complex categorical 
variables is cumbersome at best when estimating such models. These models would not allow us to use the detailed categorization of household types, which we believe is crucial to investigating the effects of household responsibilities on gendered travel behavior.

\section{Descriptive analysis}

The descriptive analysis of our data set starts with an overview of trip frequencies for different groups of men and women (Table 3). In the survey, a trip is defined as movement longer than 500 meters with specific travel purpose. Compared to men, women make more trips per day; they take more shopping trips but fewer leisure trips. This is finding in line with mainstream research on gender differences in Western countries (Hanson \& Hanson, 1980; Turner \& Niemeier, 1997). When differentiating for trip purposes, the presence of children increases trip making for other purposes, which primarily refers to accompanying children to or from school, whereas it reduces trips for shopping and leisure. The presence of grandparents tends to diminish the shopping trips of the young parents while increasing leisure trips.

Between different household types, women's daily trip frequencies vary more than men's, suggesting that varying household responsibilities influence women more profoundly. People in core families take the most trips per day, whereas those in adult households take the fewest trips. This is unsurprising given that the household size of adult households is generally larger than that of core families; there are more adults to share household responsibilities, which could result in fewer trips per person. At the same time, women and men in core families show the greatest differences in trip frequencies, but they have virtually the same number of trips as adult households. It might be concluded that the presence of children has an augmenting effect on the number of trips of the young parents and widens the travel gaps between their mothers and fathers. On the contrary, the presence of aged parents tends to reduce the trip making of the young parents and diminish gender differences. These outcomes support the HRH and our hypothesis that parents and parents-in-law will share responsibilities, thus diminishing the gender differences of the children's parents in terms of travel behavior.

Table 4 gives an overview of the travel distances of men and women in different household types. Women in our sample travel markedly shorter distances per day than

Table 3. Travel frequencies of males and females in different household types.

\begin{tabular}{llcccccc}
\hline & & Sample size & Work & Shopping & Leisure & Other & Total \\
\hline Single & Male & 63 & 0.78 & 0.13 & 0.50 & 0.06 & 1.47 \\
Couple & Female & 23 & 0.56 & 0.53 & 0.41 & 0.11 & 1.62 \\
& Male & 140 & 0.57 & 0.29 & 0.48 & 0.18 & 1.52 \\
Core families & Female & 140 & 0.48 & 0.47 & 0.46 & 0.06 & 1.46 \\
& Male & 450 & 0.97 & 0.11 & 0.16 & 0.28 & 1.52 \\
Adult households & Female & 450 & 0.95 & 0.31 & 0.14 & 0.26 & 1.67 \\
\multirow{4}{*}{ Extended households } & Male & 316 & 0.84 & 0.11 & 0.23 & 0.19 & 1.37 \\
& Female & 316 & 0.80 & 0.20 & 0.22 & 0.16 & 1.38 \\
Total & Male & 96 & 0.96 & 0.07 & 0.21 & 0.28 & 1.52 \\
& Female & 96 & 0.94 & 0.20 & 0.14 & 0.22 & 1.50 \\
& Male & 1,065 & 0.85 & 0.15 & 0.25 & 0.25 & 1.49 \\
& Female & 1,025 & 0.81 & 0.31 & 0.23 & 0.19 & 1.54 \\
\hline
\end{tabular}

Source: Own calculation based on data of NRTS 2008. 
Table 4. The mean travel distances of males and females in different household types $(\mathrm{km})$.

\begin{tabular}{llccccc}
\hline & & Work & Shopping & Leisure & Other & Total \\
\hline Single & Male & 4.5 & 1.5 & 2.5 & 2.5 & 4.3 \\
Couple & Female & 5.5 & 2.3 & 2.5 & 8.0 & 5.8 \\
& Male & 4.1 & 2.0 & 3.4 & 3.3 & 4.5 \\
Core families & Female & 3.7 & 1.8 & 3.0 & 3.2 & 3.7 \\
& Male & 3.9 & 1.8 & 2.5 & 5.1 & 5.0 \\
Adult households & Female & 3.0 & 1.7 & 2.9 & 2.7 & 3.8 \\
\multirow{4}{*}{ Extended households } & Male & 4.7 & 2.6 & 3.3 & 4.5 & 5.5 \\
& Female & 4.4 & 2.7 & 2.9 & 5.0 & 4.7 \\
Total & Male & 4.5 & 1.7 & 4.0 & 3.2 & 5.7 \\
& Female & 4.4 & 1.5 & 4.0 & 4.1 & 5.2 \\
& Male & 4.2 & 2.0 & 3.2 & 4.5 & 5.0 \\
& Female & 3.5 & 1.9 & 3.0 & 3.5 & 4.2 \\
\hline
\end{tabular}

Source: Own calculation based on data of NRTS 2008.

men, which again is comparable to outcomes of research in the West (Rosenbloom, 2006). The reason could be that women encounter more space-time fixity than men in the same households because their activities are pegged around these fixities. This would result in shorter travel distances. As expected, the difference primarily relates to the much longer commutes of men and differences relating to trips for "other" purposes: for men, 66\% of "other trips" involve longer distance work-related travel, whereas for women, $55 \%$ of "other trips" are more locally oriented trips to accompany children to and from school.

The travel distance for women varies more considerably between household types than for men, particularly when commuting is the purpose of travel. Along with the results of trip frequencies, this finding again suggests that women are more sensitive to varying household responsibilities. The commuting distances are longest for singles. It seems that with diminished household responsibilities, compared to people in core families, both women and men in other households tend to experience relatively low levels of space-time fixities. Therefore, they can commute longer distances in search of better employment opportunities. This result corroborates that of Kwan (1999). Household responsibilities increase when people transition from a single-person household to a couple's household, and they increase again when they have children. With these transformations, both men and women shorten their commutes. Although the shorter commuting distances of women could be attributed to various reasons, such as less access to private cars, working duration and personal preferences for work, the greater household responsibilities for women might also be a possible reason. The presence of aged parents in the household seems to release adult children, particularly women, from household responsibilities. The presence of aged parents in the household thus limits the gender differences in trip frequencies and the trip distances between men and women.

There is a notable difference in our sample in terms of travel behavior in Western cities: single females commute longer distances than single males (Crane, 2007). This result is in line with research in Tokyo (Kawase, 2004). One possible reason could be that traditional norms imply that unmarried daughters are less likely to live alone; they have to live with their parents or in dormitories shared with other single women. As a result, they have fewer residential choices with short commuting distances. Another explanation is 
related to housing provided by companies. In general, there is a lack of dormitories and company houses for women compared to men (Smith \& Pun, 2006).

\section{Multivariate analysis}

\section{Travel frequency}

Table 5 shows that none of the household types correlates significantly with commuting trip making by men, whereas women in adult households make significantly fewer trips than women in core families. This result could be explained by the fact that part-time jobs are almost non-existent in China. As a result, like men, working women have to commute

Table 5. Regression model for commuting trip frequencies.

\begin{tabular}{|c|c|c|c|c|c|c|}
\hline & \multicolumn{2}{|c|}{ Total } & \multicolumn{2}{|c|}{ Male } & \multicolumn{2}{|c|}{ Female } \\
\hline & Coef. & $\begin{array}{l}\text { Odds } \\
\text { ratio }\end{array}$ & Coef. & $\begin{array}{l}\text { Odds } \\
\text { ratio }\end{array}$ & Coef. & $\begin{array}{l}\text { Odds } \\
\text { ratio }\end{array}$ \\
\hline $\begin{array}{l}\text { Gender }(\text { Male }=\text { ref. }) \\
\text { Female }\end{array}$ & 0.088 & 1.092 & & & & \\
\hline $\begin{array}{l}\text { Age }(20-29=\text { ref. }) \\
30-39 \\
40-49 \\
50-60 \\
\text { More than } 60\end{array}$ & $\begin{array}{l}0.363^{* * *} \\
0.505^{* * *} \\
0.381 * * \\
-0.291\end{array}$ & $\begin{array}{l}1.438 \\
1.657 \\
1.464 \\
0.748\end{array}$ & $\begin{array}{l}0.444 * * * \\
0.460 * * * \\
0.312 \\
0.620\end{array}$ & $\begin{array}{l}1.559 \\
1.584 \\
1.366 \\
1.859\end{array}$ & $\begin{array}{l}0.273^{* *} \\
0.566^{* * *} \\
0.590^{*} \\
-1.457^{* *}\end{array}$ & $\begin{array}{l}1.313 \\
1.761 \\
1.805 \\
0.233\end{array}$ \\
\hline $\begin{array}{l}\text { Education (Primary school and belov } \\
\text { Middle and high school } \\
\text { College and above }\end{array}$ & $\begin{array}{r}v=\text { ref.) } \\
0.133 \\
0.053\end{array}$ & $\begin{array}{l}1.142 \\
1.055\end{array}$ & $\begin{array}{l}0.053 \\
0.029\end{array}$ & $\begin{array}{l}1.055 \\
1.030\end{array}$ & $\begin{array}{l}0.115 \\
0.027\end{array}$ & $\begin{array}{l}1.122 \\
1.027\end{array}$ \\
\hline $\begin{array}{l}\text { Occupation (Factory workers = ref.) } \\
\text { Service personnel } \\
\text { Staff and civil servant } \\
\text { Self-employment } \\
\text { Other jobs }\end{array}$ & $\begin{array}{l}-0.054 \\
0.172^{*} \\
-0.480^{* * *} \\
-0.035\end{array}$ & $\begin{array}{l}0.947 \\
1.188 \\
0.619 \\
0.965\end{array}$ & $\begin{array}{l}-0.176 \\
-0.061 \\
-0.623 * * * \\
-0.048\end{array}$ & $\begin{array}{l}0.839 \\
0.941 \\
0.536 \\
0.953\end{array}$ & $\begin{array}{l}0.142 \\
0.453^{* * *} \\
-0.363^{* *} \\
0.137\end{array}$ & $\begin{array}{l}1.153 \\
1.573 \\
0.696 \\
1.147\end{array}$ \\
\hline $\begin{array}{l}\text { Household car ownership (Non-car = } \\
\text { Car ownership (having car) }\end{array}$ & $\begin{array}{l}=\text { ref.) } \\
-0.085\end{array}$ & 0.919 & -0.127 & 0.880 & -0.024 & 0.976 \\
\hline $\begin{array}{l}\text { Annual household income (EUR, } \\
\text { Less than } 2,000 \\
2,000-5,000\end{array}$ & $\begin{array}{l}\text { re than } 5, \\
-0.101 \\
0.042\end{array}$ & $\begin{array}{c}0=\text { ref.) } \\
0.904 \\
1.042\end{array}$ & $\begin{array}{l}0.002 \\
0.004\end{array}$ & $\begin{array}{l}1.002 \\
1.004\end{array}$ & $\begin{array}{r}-0.199 \\
0.076\end{array}$ & $\begin{array}{l}0.820 \\
1.079\end{array}$ \\
\hline $\begin{array}{l}\text { Household type (core families = ref.) } \\
\text { Single } \\
\text { Couple } \\
\text { Adult households } \\
\text { Extended households } \\
\text { Population density } \\
\text { Distance to the nearest metro station }\end{array}$ & $\begin{array}{l} \\
0.279 \\
-0.169^{*} \\
-0.294^{* * *} \\
-0.010 \\
0.019 \\
-0.019^{*}\end{array}$ & $\begin{array}{l}1.322 \\
0.845 \\
0.746 \\
0.990 \\
1.019 \\
0.981\end{array}$ & $\begin{array}{r}-0.102 \\
-0.114 \\
-0.168 \\
-0.030 \\
0.018 \\
-0.008\end{array}$ & $\begin{array}{l}0.903 \\
0.892 \\
0.845 \\
0.970 \\
1.018 \\
0.992\end{array}$ & $\begin{array}{l}-0.174 \\
-0.239 \\
-0.426^{* * *} \\
0.001 \\
0.025 \\
-0.027^{*}\end{array}$ & $\begin{array}{l}0.840 \\
0.788 \\
0.653 \\
1.001 \\
1.026 \\
0.974\end{array}$ \\
\hline $\begin{array}{l}\text { Threshold1 } \\
\text { Threshold } 2 \\
\text { Pseudo } R^{2} \\
\text { Number of obs. }\end{array}$ & $\begin{aligned}-1.013(1 \mathrm{t} \\
1.669(2 \mathrm{t} \\
0.059 \\
2,090\end{aligned}$ & $\begin{array}{l}\text { rips) } \\
\text { rips) }\end{array}$ & $\begin{aligned}-1.289(1 \mathrm{tt} \\
1.515(2 \mathrm{tr} \\
0.077 \\
1,065\end{aligned}$ & $\begin{array}{l}\text { ip) } \\
\text { ips) }\end{array}$ & $\begin{array}{l}-0.877(1 \mathrm{t} \\
1.771(2 \mathrm{t} \\
0.075 \\
1,025\end{array}$ & $\begin{array}{l}\text { ips) } \\
\text { ips) }\end{array}$ \\
\hline
\end{tabular}

Note: $* a \leq 0.10 ; * * a \leq 0.05 ; * * * a \leq 0.001$.

Source: Own calculation based on data of NRTS 2008. 
every day. Women in adult households make significantly fewer trips than women in core families, which is result of their return trips home at lunchtime. There are several possible reasons for women's return trips home at lunchtime in core families, such as a short working duration and commuting distance, the use of individual transportation modes, and long lunch breaks. However, taking care of children during lunchtime could also be one possible reason. Adult households contain no children; furthermore, the elderly parents could take on some of the household responsibilities, which could alleviate women from returning home midday.

Age exerts significant influences on commuting trip making by both genders. Young people tend to make significantly fewer commuting trips than the elderly. This result could be due to the longer average commuting distances of young people, as shown by our data, which could limit their opportunities to commute more than once a day. Working women older than 60 years are an exception to this rule. Because these women are usually rehired after retirement, they do not need to work every day (but due to the small size of this subgroup, these women are not included as part-time workers in the statistics). As a result, they make fewer commuting trips. In comparison to factory workers, female staff and civil servants tend to take more commuting trips, which might reflect larger financial budgets. Because female staff and civil servants earn more, they can afford houses closer to their workplaces, which are usually located near the city center, and thus make shorter commutes. The self-employed have a lower number of commuting trips than factory workers. They have more flexible working-schedules, and they work from home more often.

The distance to the nearest metro station has a significant effect on women's commuting trip making. If women live further away from a metro station, they make fewer trips. However, the distance to the nearest metro station does not have a significant effect on the trip making of men. This finding might be related to the distribution of different types of employment. Underground stations usually have rich female-dominant occupation opportunities, given that underground stations are places where shops are concentrated.

Table 6 shows significant gender differences in terms of shopping trips. Women take more trips than men, which is consistent with findings in Western cities (Kwan, 2000; Turner \& Niemeier, 1997). This finding also lends support to the HRH, which holds that women share more household responsibilities and thus make more shopping trips.

Household type, again, is significant for only the shopping trip making of women. Women in adult households and extended households tend to make fewer shopping trips than those in core families, a finding that can be attributed to the presence of elderly parents in the household who share responsibilities.

Age has a significant influence on the shopping trip making of women. The amount of trips increase for older women. This finding reflects lifestyle differences between young and old women. A larger share of young women goes to the supermarket once or twice a week. Older women, however, are more likely to maintain a traditional shopping habit of daily visits to street stalls (Davis, 2000). Furthermore, young people are also more likely to live in commodity housing estates in suburban areas, where shopping facilities are scarcer and trips are thus less frequent than in the city center (Feng \& Zhou, 2005).

Education has no significant effect on the shopping trip making of women, but higher education results in fewer shopping trips for men. This finding is in line with the relative resource hypothesis, which holds that men with lower education have fewer resources, which results in increased household responsibilities (Wang et al., 2010). However, this 
Table 6. Regression model for shopping trip frequencies.

\begin{tabular}{|c|c|c|c|c|c|c|}
\hline & \multicolumn{2}{|c|}{ Total } & \multicolumn{2}{|c|}{ Male } & \multicolumn{2}{|c|}{ Female } \\
\hline & Coef. & $\begin{array}{l}\text { Odds } \\
\text { ratio }\end{array}$ & Coef. & $\begin{array}{l}\text { Odds } \\
\text { ratio }\end{array}$ & Coef. & $\begin{array}{l}\text { Odds } \\
\text { ratio }\end{array}$ \\
\hline $\begin{array}{l}\text { Gender }(\text { Male = ref. }) \\
\text { Female }\end{array}$ & $0.506 * * *$ & 1.659 & & & & \\
\hline $\begin{array}{l}\text { Age }(20-29=\text { ref. }) \\
30-39 \\
40-49 \\
50-60 \\
\text { More than } 60\end{array}$ & $\begin{array}{l}0.195^{*} \\
0.317^{* * *} \\
0.205 \\
0.456^{* *}\end{array}$ & $\begin{array}{l}1.215 \\
1.373 \\
1.228 \\
1.578\end{array}$ & $\begin{array}{l}-0.030 \\
0.065 \\
0.212 \\
0.328\end{array}$ & $\begin{array}{l}0.970 \\
1.067 \\
1.236 \\
1.389\end{array}$ & $\begin{array}{l}0.320^{* *} \\
0.476^{* * *} \\
0.209 \\
0.506^{* *}\end{array}$ & $\begin{array}{l}1.378 \\
1.610 \\
1.233 \\
1.658\end{array}$ \\
\hline $\begin{array}{l}\text { Education (Primary school and below } \\
\text { Middle and high school } \\
\text { College and above }\end{array}$ & $\begin{array}{l}=\text { ref.) } \\
-0.032 \\
-0.163\end{array}$ & $\begin{array}{l}0.968 \\
0.850\end{array}$ & $\begin{array}{l}-0.346^{* *} \\
-0.308^{*}\end{array}$ & $\begin{array}{l}0.708 \\
0.735\end{array}$ & $\begin{array}{l}0.123 \\
-0.128\end{array}$ & $\begin{array}{l}1.131 \\
0.880\end{array}$ \\
\hline $\begin{array}{l}\text { Occupation (Factory workers = ref.) } \\
\text { Service personnel } \\
\text { Staff and civil servant } \\
\text { Self-employment } \\
\text { Other jobs } \\
\text { No job }\end{array}$ & $\begin{array}{l}0.071 \\
-0.079 \\
0.108 \\
-0.225^{*} \\
1.062^{* * *}\end{array}$ & $\begin{array}{l}1.074 \\
0.924 \\
1.114 \\
0.798 \\
2.893\end{array}$ & $\begin{array}{l}0.270 \\
-0.139 \\
0.212 \\
-0.307 \\
1.120^{* * *}\end{array}$ & $\begin{array}{l}1.311 \\
0.871 \\
1.236 \\
0.736 \\
3.065\end{array}$ & $\begin{array}{l}-0.043 \\
0.001 \\
0.002 \\
-0.231 \\
1.058^{* * *}\end{array}$ & $\begin{array}{l}0.958 \\
1.001 \\
1.002 \\
0.793 \\
2.882\end{array}$ \\
\hline $\begin{array}{l}\text { Household car ownership (Non-car }= \\
\text { Car ownership (having car) }\end{array}$ & $\begin{array}{l}\text { ref.) } \\
-0.012\end{array}$ & 0.989 & 0.057 & 1.058 & -0.055 & 0.947 \\
\hline $\begin{array}{l}\text { Annual household income (EUR, Mo } \\
\text { Less than } 2,000 \\
2,000-5,000 \\
\text { Household type (core families = ref.) }\end{array}$ & $\begin{array}{l}\text { re than } 5,000 \\
-0.127 \\
-0.243^{* *}\end{array}$ & $\begin{array}{l}=\text { ref.) } \\
0.881 \\
0.785\end{array}$ & $\begin{array}{l}-0.238 \\
-0.245^{*}\end{array}$ & $\begin{array}{l}0.789 \\
0.783\end{array}$ & $\begin{array}{l}-0.076 \\
-0.245^{* *}\end{array}$ & $\begin{array}{l}0.927 \\
0.783\end{array}$ \\
\hline $\begin{array}{l}\text { Single } \\
\text { Couple } \\
\text { Adult households } \\
\text { Extended households } \\
\text { Population density } \\
\text { Distance to the nearest metro station }\end{array}$ & $\begin{array}{l}0.007 \\
0.017 \\
-0.132 \\
-0.279^{* *} \\
-0.078^{* * *} \\
-0.026^{* *}\end{array}$ & $\begin{array}{l}1.007 \\
1.017 \\
0.876 \\
0.757 \\
0.925 \\
0.974\end{array}$ & $\begin{array}{l}-0.501 \\
0.004 \\
0.029 \\
-0.200 \\
-0.080^{* *} \\
-0.014\end{array}$ & $\begin{array}{l}0.606 \\
1.004 \\
1.030 \\
0.819 \\
0.923 \\
0.986\end{array}$ & $\begin{array}{l}0.336 \\
0.027 \\
-0.258^{* *} \\
-0.310^{*} \\
-0.078^{* * *} \\
-0.034^{* *}\end{array}$ & $\begin{array}{l}1.399 \\
1.027 \\
0.772 \\
0.733 \\
0.925 \\
0.966\end{array}$ \\
\hline $\begin{array}{l}\text { Threshold1 } \\
\text { Threshold } 2 \\
\text { Pseudo } R^{2} \\
\text { Number of obs. }\end{array}$ & $\begin{array}{l}1.026(1 \mathrm{tri} \\
2.725(2 \mathrm{tri} \\
0.171 \\
2,090\end{array}$ & & $\begin{array}{l}0.778(1 \mathrm{t} \\
2.205(2 \mathrm{t} \\
0.159 \\
1,065\end{array}$ & & $\begin{array}{l}0.625(1 \text { tri } \\
2.493(2 \text { tri } \\
0.155 \\
1,025\end{array}$ & \\
\hline
\end{tabular}

Note: $* a \leq 0.10 ; * * a \leq 0.05 ; * * * a \leq 0.001$.

Source: Own calculation based on data of NRTS 2008.

does not hold for women, possibly due to the nature of purchases. In addition to shopping activities for household goods, women might also have to shop for personal needs more frequently than men, regardless of their education (Srinivasan \& Bhat, 2005). Therefore, shopping is seen to be more obligatory for women than men. Occupation significantly correlates to only the jobless, who make more shopping trips as a result of smaller spatialtemporal constraints. Population density shows almost equal negative effects on the shopping trip making of men and women, with higher densities resulting in fewer shopping trips. This finding can be attributed to the fact that trip chaining is easier in areas with high densities (Schwanen et al., 2007). The distance to the nearest metro station has a negative effect on shopping: The amount of shopping trips diminishes when the 
metro station is further away. This finding makes intuitive sense given that metro stations are usually places where shops are concentrated.

The above analysis shows significant gender and household differences in shopping trip making. However, we are also interested in gender differences in different household types. Therefore, we conducted a separate model for shopping trips for people of different household types. (Due to space limitations, we cannot include the table in the paper.) The sample size for 'singles' did not meet the requirements of the regression model and consequently were excluded from the analysis. The resulting model shows that women in "couples" and "core families" make significantly more shopping trips than men, whereas there are no significant differences between women and men in "adult households" and "extended households". This finding reconfirms the HRH, which holds that women tend to share more household responsibilities in couples' households and families, and the $\mathrm{ECH}$ of this paper, which holds that the presence of elderly parents in households diminishes gender differences.

\section{Travel distance}

Table 7 presents our regression model for commuting distances. It shows that men have significantly longer commutes than women. Household type contributes substantially to the $R^{2}$ of the models but much more so for women than men, which implies that particularly for women, household type is a decisive factor for commuting distance. A comparison of the coefficients for different household types shows that for both men and women, commutes are longest for singles, decrease for couples, and are lowest for people in core families, but they rise again for members of adult households and extended households. Differences among household types are larger for women. The results support both the HRH and the ECH.

Findings in the United States of America indicate that the presence of children in households reduces commuting distances for women but not for men (Turner \& Niemeier, 1997). By contrast, our analysis shows that in Nanjing, this effect on commuting distance is visible for both men and women. This finding could be attributed to the high employment ratios of women in China, which require men to share some of the child caring tasks. The model also demonstrates that men and women in adult households and extended households commute significantly longer than members of core families. Strikingly, the gender differences in commuting length in those households are equalized.

Age has a more pronounced correlation with commuting distance for women than for men. This finding could be the result of cohort effects regarding women's preferences for and attitudes toward work in different life stages (Collins \& Tisdell, 2002). As age increases, women in East Asia tend to put more emphasis on household tasks over their careers. Consequently, they might be less willing to take long journeys to work (Lee \& McDonald, 2003).

Strikingly, education and occupation do not significantly affect the commuting distances of women. This finding is inconsistent with existing research in Western cities that shows that highly educated women have longer commutes (Schwanen et al., 2007). Apparently, the relative resource hypothesis that stresses the importance of resources of women to negotiate with their partners regarding household responsibilities does not provide an adequate explanation in the Chinese context. It could be that cultural ideologies toward female roles are so strong that increased resources do not lead to adjusted distributions in household responsibilities. Alternatively, this dynamic could also result from labor market characteristics. Fan and Regulska (2008) show that women in China 


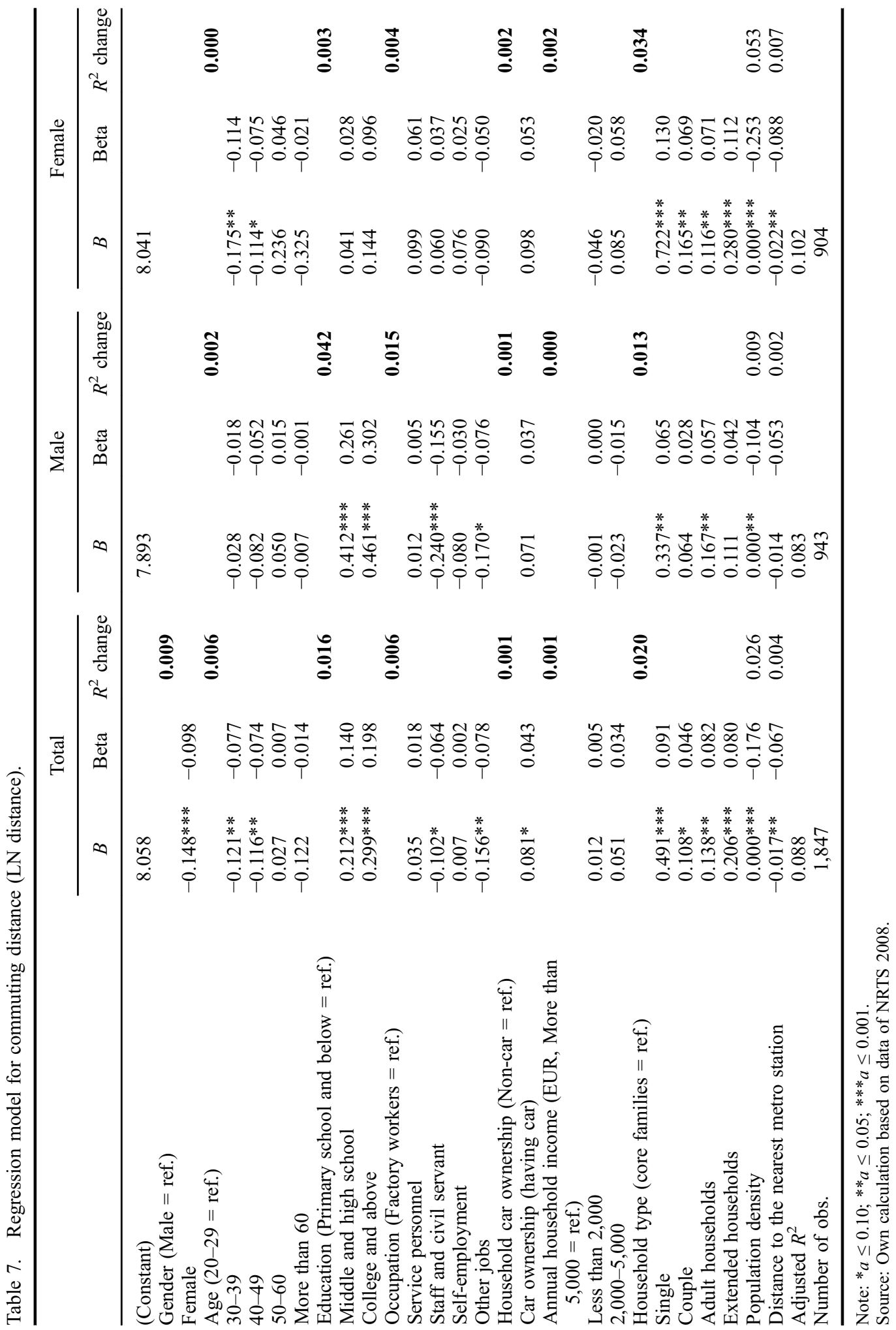


usually occupy lower positions, and even in highly professional jobs, they earn much less money than men. The resulting income differences between men and women for all levels of education might explain the limited effect of education and occupation on travel distances.

Population density correlates negatively with commuting distance, meaning that people in areas with high population densities travel less. However, this effect is much stronger for women than for men, so the travel behavior of women is more sensitive to differences in population density. This effect fits in with traditional cultural patterns, which accord the role of the main breadwinner in the households to men. Men thus search for high-paid job opportunities all over the metropolitan area, whereas women have to combine work with household responsibilities and look for jobs that are close to home (Madden, 1981). Therefore, for the women who seek to minimize the distance traveled to work, population density tends to have a larger effect on women than on men. The distance to the nearest metro station also has a stronger influence on the commuting distances of women. This might be related to the distribution of different types of employment. Underground stations usually provide female-dominated occupation opportunities because underground stations are places where shops are concentrated.

Table 8 presents a regression model for the shopping distances of men and women. In line with the descriptive analysis, the model shows no significant gender differences. Women in core families travel shorter distances than women in adult households for shopping. Women in core families make significantly more trips for shopping; this result suggests that elderly co-residence frees parents from household responsibilities so that they can shop over larger distances. The fact that there is no significant difference in the shopping distances of men between household types suggests that males' household responsibilities do not vary as much as females' responsibilities among the different household types. This observation could be supported by the results in Table 3, which shows that male shopping frequencies vary less than female frequencies.

The shopping distances of women decrease as age increases. This finding reconfirms the different shopping habits of women of different ages: young women are more likely to go to supermarkets located at relatively larger distances from home, whereas older women tend to visit local street stalls (Collins \& Tisdell, 2002). Another possible reason is that older women are more likely than younger women to use non-motorized transportation modes, so they cannot cover longer shopping distances.

Occupation exerts a significant influence on shopping distance for both men and women. In comparison to factory workers, other people seem to travel longer distances for shopping. Because factory workers usually have lower incomes, they can afford less specialized shopping and thus can meet their needs at local shopping facilities (Wong \& Yu, 2002). The spatial structure characteristics of factories could also be a factor; they tend to be located in industrial districts, which have fewer shopping opportunities than office districts. In contrast to the model for commuting distance, men's shopping travel distances are more sensitive to built environment characteristics. This finding might result from the fact that women are primarily responsible for daily shopping activities, whereas men primarily participate in non-daily shopping (Crane, 2007). Daily shopping facilities are dispersed throughout the urban area, whereas non-daily shopping facilities are primarily concentrated in city centers. Thus, the variations of shopping distances for men in different areas are much larger than for women. The same logic holds for the 


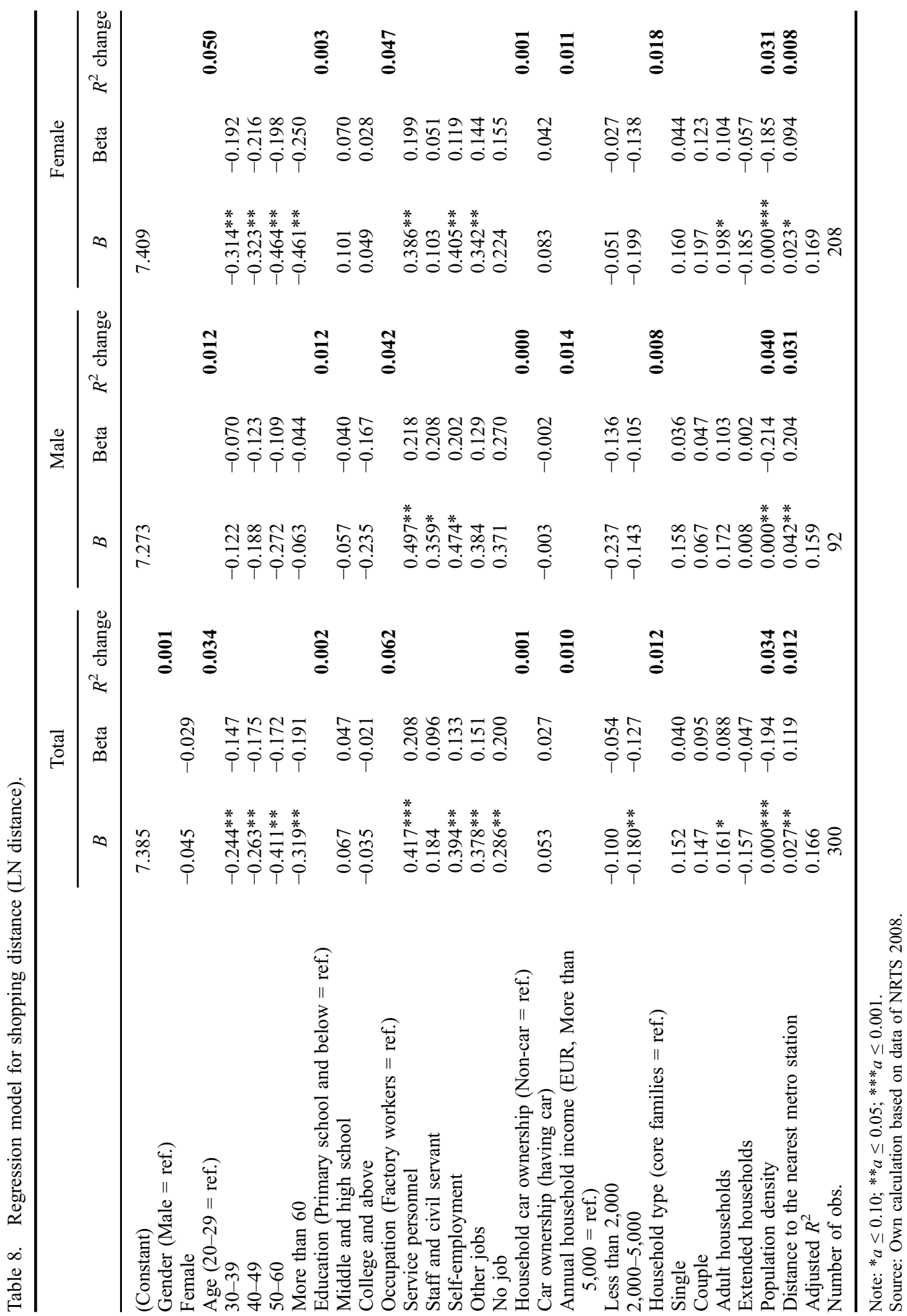


distance to the nearest metro station because metro stations are usually located in shopping centers.

Similar to the analysis of trip generation, we were again keen to know whether there are gender differences in travel distances between different household types. Our analysis shows that gender and household type have a more pronounced effect on commuting distances, so we focused on only commuting. We again conducted separate models for the commuting distances of people from different household types (except for "single"). The results (which are not shown due to space limitations) show significant gender differences for couples and core families but negligible differences in adult households and extended households. These results are in line with previous findings that the sharing of household responsibilities by other adults in the household diminishes temporal-spatial constraints for both women and men (Kwan, 1999). However, it seems that the reduction effect is more obvious for women. As a result, gender differences in travel in households with elderly parents become negligible.

\section{Discussion and conclusion}

Research on the role of gender in travel behavior, from the perspectives of both theoretical reasoning and empirical results, is dominantly developed in the Western context. The HRH, which provides the dominant theoretical explanation for gender differences in this literature, does not take into account household types that are not common in Western countries. This paper aims to fill this gap with a study of the effects of co-residence with the elderly on gender differences in travel behavior. For this reason, we formulated the following research question: what are the determinants of gendered differences in travel behavior, and specifically, what are the effects of elderly co-residence in households and land use on gender differences in trip frequency and travel distance?

Our analysis shows that for commuting, women in core families travel shorter distances while making more trips than women in couples or single women. At the same time, gender differences increase significantly for women in core families. This observation is in line with the HRH, which sees the reason for this result as rooted in the larger share of women in household responsibilities. At the same time, our research shows that women in adult households and extended households travel less frequently but over larger distances than women in core families. In addition, in adult households and extended households, there are no significant gender differences in commuting distances. We can explain this result based on the participation of elderly parents in household responsibilities, which supports our ECH.

In contrast to the existing literature, which focuses primarily on commutes, we also conducted an analysis of gender differences in shopping. Our analysis shows that women in couples and core families tend to make significantly more shopping trips than men but that these differences become negligible in adult households and extended households. Though there are no direct data on the participation of elderly co-residents in household tasks, the negligible gendered differences in the travel behavior of those households could be the result of the help of elderly parents in household responsibilities, which again supports our ECH.

The results show that the presence of aged parents that can share household responsibilities reduces the burden of temporal-spatial constraints on women. The findings support the idea that household responsibilities are a crucial factor for gender differences in travel behavior. They explain the gender differences in the travel behavior of not only 
singles, couples and core families but also adult households and extended households. In this sense, our ECH is not an alternative to the HRH but instead extends the basic ideas of this hypothesis to another context. Other possibilities, such as paid services (e.g., babysitters) could have the same effects. The most important implication of this finding is that redressing the household tasks within the household would substantially reduce women's temporal-spatial constraints, which might also improve the labor market position and income-earning potential of women.

We also include some built environment characteristics in our models, which bring us to the second part of the research question. Our analysis shows that built environment characteristics have different relationships to the travel behavior of men and women. Due to better opportunities for chain trips, women in dense areas travel shorter distances than women in less dense areas, whereas this effect is not pronounced for men. For shopping, the relationships are reversed with men in dense areas traveling shorter distances than men in suburban areas, whereas shopping distances for women remain relatively the same. For commuting, these differences reflect the fact that men tend to choose employment opportunities from all over the metropolitan area, whereas women are more likely to confine themselves to local workplaces. The sensitivity of shopping distances of men to built environment characteristics can be attributed to the fact that men undertake more non-daily shopping. These facilities are not as evenly distributed over the metropolitan area as are daily shopping facilities.

The results of this paper are interesting not only from a theoretical point of view but also from a policy-making perspective. The conclusion that elderly co-residence frees adult women from household responsibilities and diminishes gender differences in travel behavior is insightful for countries that want to encourage female participation in the labor market, but it is not very likely that these household types will become prevalent in Western individualized societies. However, within reasonable distances, highly mobile elderly people in Western countries can also take care of their grandchildren. In addition, a well-developed daily care system could also take over the household responsibilities of women, thus fostering gender equality in travel behavior.

Due to data limitations, unfortunately, we could not control for the health conditions of the elderly, and we did not examine gender relations in households where the elderly themselves need care. Meanwhile, in our data, we cannot distinguish shopping for the household and shopping for personal needs, which are essentially different activities. Mixing them together might weaken some points of the paper. All in all, we should keep in mind that the distributions of household responsibilities and the resultant activity-travel behavior of household members are more complex than we had imagined. To deepen our understanding of the influence of household responsibilities on the activity-travel patterns of household members, future studies should consider more possibilities, such as joint activities. A detailed study of the mobility of adults in adult households and extended households would also be relevant. In addition, the attributes of activities related to household tasks, such as purpose, duration, timing, location and the person involved - the context of the activities - could have different effects on gendered travel behavior (Schwanen et al., 2008). In the future, these topics deserve additional research.

\section{Disclosure statement}

No potential conflict of interest was reported by the authors. 


\section{Funding}

This research has been supported by the National Natural Science Foundation of China [41401150].

\section{References}

Becker, Gary (1971). The economics of discrimination. Chicago, IL: University of Chicago Press.

Chen, Xuan, \& Silverstein, Merril (2000). Intergenerational social support and the psychological well-being of older parents in China. Research on Aging, 22, 43-65. doi:10.1177/ 0164027500221003

Cohen, Philip (1998). Replacing housework in the service economy: Gender, class, and raceethnicity in service spending. Gender \& Society, 12, 219-231. doi:10.1177/ 089124398012002006

Collins, Desmond H., \& Tisdell, Clement A. (2002). Gender and differences in travel life cycles. Journal of Travel Research, 41, 133-143. doi:10.1177/004728702237413

Crane, Randall (2007). Is there a quiet revolution in women's travel? Revisiting the gender gap in commuting. Journal of the American Planning Association, 73, 298-316. doi:10.1080/ 01944360708977979

Cullen, Ian (1979). Timing space and spacing time by Tommy Carlstein; Don Parkes; Nigel Thrift. The Town Planning Review, 50, 377-378.

Davis, Deborah S. (2000). The consumer revolution in urban China. Berkeley: University California Press.

Dijst, Martin, \& Vidakovic, Velibor (2000). Travel time ratio: The key factor of spatial reach. Transportation, 27, 179-199. doi:10.1023/A:1005293330869

Du, Fenglian, \& Dong, Xiaoyuan (2013). Women's employment and child care choices in urban China during the economic transition. Economic Development and Cultural Change, 62, 131155. doi: $10.1086 / 671714$

Ewing, Reid, \& Cervero, Robert (2001). Travel and the built environment: A synthesis. Transportation Research Record, 1780, 87-114. doi:10.3141/1780-10

Fan, Cindy C., \& Regulska, Joanna (2008). Gender and the labor market in China and Poland. In J. R. Logan (editor), Urban China in transition (pp. 89-111). Oxford: Blackwell.

Federal Statistical Office. (2008). Equal opportunities for women and men: Switzerland in international comparison. Selected indicators on equal opportunities in the areas of education, work and politics. Neuchâtel: FSO.

Feng, Jian, \& Zhou, Yixing (2005). Suburbanization and the changes of urban internal spatial structure in Hangzhou, China. Urban Geography, 26, 107-136. doi:10.2747/02723638.26.2.107

Feng, Jianxi, Dijst, Martin, Prillwitz, Jan, \& Wissink, Bart (2013). Travel time and distance in international perspective: A comparison between Nanjing (China) and the Randstad (The Netherlands). Urban Studies, 50, 2993-3010. doi:10.1177/0042098013482504

Goh, Esther C. L. (2009). Grandparents as childcare providers: An in-depth analysis of the case of Xiamen, China. Journal of Aging Studies, 23, 60-68. doi:10.1016/j.jaging.2007.08.001

Hägerstraand, Torsten (2005). What about people in regional science? Papers in Regional Science, 24, 7-24. doi:10.1111/j.1435-5597.1970.tb01464.x

Hall, Derek (2004). Towards a gendered transport geography. Journal of Transport Geography, 12, 245-247. doi:10.1016/j.jtrangeo.2004.04.003

Hanson, Susan (1982). The determinants of daily travel-activity patterns: Relative location and socio-demographic factors. Urban Geography, 3, 179-202. doi:10.2747/0272-3638.3.3.179

Hanson, Susan, \& Hanson, Perry (1980). Gender and urban activity patterns in Uppsala, Sweden. Geographical Review, 70, 291-299.

Hanson, Susan, \& Johnston, Ibipo (1985). Gender differences in work-trip length: Explanations and implications. Urban Geography, 6, 193-219. doi:10.2747/0272-3638.6.3.193

Hanson, Susan, Kominiak, Tara, \& Carlin, Scott (1997). Assessing the impact of location on women's labor market outcomes: A methodological exploration. Geographical Analysis, 29, 281-297. doi:10.1111/j.1538-4632.1997.tb00965.x

Hanson, Susan, \& Pratt, Geraldine (1988). Spatial dimensions of the gender division of labor in a local labor market. Urban Geography, 9, 180-202. doi:10.2747/0272-3638.9.2.180

Hanson, Susan, \& Pratt, Geraldine (1990). Geographic perspectives on the occupational segregation of women. National Geographic Research, 6, 376-399. 
Hubers, Christa, Schwanen, Tim, \& Dijst, Martin (2011). Coordinating everyday life in the Netherlands: A holistic quantitative approach to the analysis of ICT-related and other worklife balance strategies. Geografiska Annaler: Series B, Human Geography, 93, 57-80. doi:10.1111/geob.2011.93.issue-1

Kawase, Masaki (2004). Changing gender differences in commuting in the Tokyo metropolitan suburbs. Geo Journal, 61, 247-253.

Kroska, Amy (2003). Investigating gender differences in the meaning of household chores and child care. Journal of Marriage and Family, 65, 456-473. doi:10.1111/j.1741-3737.2003.00456.x

Kwan, Mei-Po (1999). Gender, the home-work link, and space-time patterns of non-employment activities. Economic Geography, 75, 370-394.

Kwan, Mei-Po (2000). Gender differences in space-time constraints. Area, 32, 145-156. doi:10.1111/area.2000.32.issue-2

Lamb, Michael E, Sternberg, Kathleen J., Hwang, Philip C., \& Broberg, Anders, G. (2014). Child care in context: Cross-cultural perspectives. London: Psychology Press.

Lee, Bun S., \& McDonald, John F. (2003). Determinants of commuting time and distance for Seoul residents: The impact of family status on the commuting of women. Urban Studies, 40, 1283-1302. doi:10.1080/0042098032000084604

MacDonald, Hamish (1999). Women's employment and commuting: Explaining the links. Journal of Planning Literature, 13, 267-283. doi:10.1177/08854129922092397

Madden, Janice F. (1981). Why women work closer to home. Urban Studies, 18, 181-194. doi:10.1080/00420988120080341

McLafferty, Sara, \& Preston, Valere (1991). Gender, race, and commuting among service sector workers. The Professional Geographer, 43, 1-15. doi:10.1111/j.0033-0124.1991.00001.x

McLafferty, Sara, \& Preston, Valerie (1992). Spatial mismatch and labor market segmentation for African American and Latina women. Economic Geography, 68, 406-431.

Nanjing Statistic Bureau. (2008). Nanjing statistic yearbook 2008. Nanjing: China Statistical Publishing House.

Rosenbloom, Sandra (2006). Understanding women's and men's travel patterns. In Transportation Research Board conference proceedings 35: Research on women's issues in transportationVolume 1: Conference overview and plenary papers (pp. 7-28). Washington, DC: TBR.

Schwanen, Tim, Ettema, Dick, \& Timmermans, Harry (2007). If you pick up the children, I'll do the groceries: Spatial differences in between-partner interactions in out-of-home household activities. Environment and Planning A, 39, 2754-2773. doi:10.1068/a38491

Schwanen, Tim, Kwan, Mei-Po, \& Ren, Fang (2008). How fixed is fixed? Gendered rigidity of space-time constraints and geographies of everyday activities. Geoforum, 39, 2109-2121. doi:10.1016/j.geoforum.2008.09.002

Smith, Chris, \& Pun, Nhai (2006). The dormitory labour regime in China as a site for control and resistance. The International Journal of Human Resource Management, 17, 1456-1470. doi: $10.1080 / 09585190600804762$

Srinivasan, Sivaramakrishnan, \& Bhat, Chandra (2005). Modeling household interactions in daily in-home and out-of-home maintenance activity participation. Transportation, 32, 523-544. doi:10.1007/s11116-005-5329-z

Susan, Hanson, \& Geraldine, Pratt (1995). Gender, work and space. London, New York: Routledge.

The Second Chinese Women's Social Status Survey Team. (2001). Main report of the second Chinese women's social status survey. Collection of Women's Studies, 5, 4-12.

Turner, Tracy, \& Niemeier, Debbie (1997). Travel to work and household responsibility: New evidence. Transportation, 24, 397-419. doi:10.1023/A:1004945903696

Wang, Zhiyun, Schoebi, Dominik, \& Perrez, Meinrad (2010). The division of family work in China and Europe: On the role of culture. Advances in Psychological Science, 18, 1668-1678.

Wong, Grace K. M., \& Yu, Lu (2002). Income and social inequality in China: Impact on consumption and shopping patterns. International Journal of Social Economics, 29, 370-384. doi:10.1108/03068290210423514

World Bank. (2013). Labor participation rate, female of the world. Washington, DC: World Bank.

Zuo, Jiping, \& Bian, Yanjie (2001). Gendered resources, division of housework, and perceived fairness - A case in urban China. Journal of Marriage and Family, 63, 1122-1133. doi:10.1111/ j.1741-3737.2001.01122.x 